University of Nebraska - Lincoln

DigitalCommons@University of Nebraska - Lincoln

Faculty Publications, Department of Psychology

Psychology, Department of

January 1999

The Ecological Validity of Jury Simulations: Is the Jury Still Out?

Brian H. Bornstein

University of Nebraska-Lincoln, bbornstein2@unl.edu

Follow this and additional works at: https://digitalcommons.unl.edu/psychfacpub

Part of the Psychiatry and Psychology Commons

Bornstein, Brian H., "The Ecological Validity of Jury Simulations: Is the Jury Still Out?" (1999). Faculty Publications, Department of Psychology. 164.

https://digitalcommons.unl.edu/psychfacpub/164

This Article is brought to you for free and open access by the Psychology, Department of at DigitalCommons@University of Nebraska - Lincoln. It has been accepted for inclusion in Faculty Publications, Department of Psychology by an authorized administrator of DigitalCommons@University of Nebraska - Lincoln. 


\title{
The Ecological Validity of Jury Simulations: Is the Jury Still Out?
}

\author{
Brian H. Bornstein, Department of Psychology, \\ Louisiana State University, Baton Rouge
}

\begin{abstract}
Despite the need to assess the ecological validity of jury simulation research before generalizing from simulations to the behavior of real jurors, surprisingly little jury research has directly addressed issues of validity. The present paper reviews the extant research on two aspects of the validity question-specifically, research that has compared different samples of mock jurors, and research that has manipulated the medium of trial presentation. In addition, jury simulation research published in the first 20 years of Law and Human Behavior is analyzed with respect to these variables. The majority of simulations used studentjurors and presented the trial in written form. Additionally, the methodology of simulation research has actually become less realistic over time. However, this trend is not necessarily cause for concern, as a review of the literature reveals little research that has obtained differences between different mock juror samples or different trial media.
\end{abstract}

Systematic research on jury decision making can be said to have two birthdates: The Chicago Jury Project (e.g., Broeder, 1959; Kalven \& Zeisel, 1966) and the inaugural issue in 1977 of Law and Human Behavior, the first journal devoted solely to interdisciplinary research in psychology and law. Because of the myriad legal and logistical problems attendant to conducting research on the decision-making processes of jurors as they serve in actual cases, the vast majority of jury research has employed simulations. Both commentators on and performers of jury research have, from the very beginning, voiced concerns about the ecological validity of jury simulations (e.g., Bray \& Kerr, 1982; Davis, Bray, \& Holt, 1977; Diamond, 1979; Gerbasi, Zuckerman, \& Reis, 1977).

The question of validity raises a number of issues (Bray \& Kerr, 1979; Diamond, 1997; Weiten \& Diamond, 1979). Major validity concerns include the mock juror sample (i.e., undergraduates vs. community-dwelling adults), the research setting (i.e., laboratory vs. courtroom), the trial medium (i.e., written summaries vs. more realistic simulations), the trial elements included (e.g., the presence or absence of deliberation), the dependent variables used (e.g., dichotomous verdicts vs. probability-of-guilt judgments), and the consequentiality of the task (i.e., making a hypothetical vs. a real decision).

These concerns are justified not only by fundamental principles governing the sound conduct of scientific research, but also by the desire to apply findings from simulation 
studies to understanding, and ultimately improving, the legal system. The courts have considered psychological research in issuing rulings on a number of topics, such as capital punishment (Ellsworth, 1988), the effects of pretrial publicity (Carroll et al., 1986), and jury decision rules (Nemeth, 1977), to mention but a few. In considering what use to make of psychological research on the jury system, the extent to which empirical findings generalize to actual settings is crucial (Carroll et al., 1986; Diamond, 1997). For example, the perceived lack of external validity has been used by the Supreme Court in choosing to discount research on the death-qualification process (Ellsworth, 1988; Thompson, 1989).

However, despite these important questions, and in spite of Bray and Kerr's (1979, p. 109) call 20 years ago "to conduct a series of careful studies that systematically explore the range of actors, behaviors, and contexts over which results of simulation studies will hold," surprisingly little research has directly addressed issues of validity. The present paper has three components: First, I review the research that has compared different samples of mock jurors. Second, I review research that has manipulated the manner of trial presentation. Although these topics have been covered recently in a general review by Diamond (1997), an extensive survey of these particular issues has not been conducted. These particular questions are chosen not because they are any more important than other validity concerns, but for three reasons: First, the mock juror sample and trial medium are methodological dimensions on which current jury simulation research displays considerable diversity, as the review makes clear. Second, they are variables that are relatively amenable to modification, should important differences be found-unlike some of the other issues, such as the consequentiality of the task (Kerr, Nerenz, \& Herrick, 1979). Third, they are among the most frequently raised issues in the constellation of factors that comprise the "validity question" (e.g., Bray \& Kerr, 1982; Davis et al., 1977; Diamond, 1997; Konecni \& Ebbesen, 1979).

The third, and final, component of the paper is an analysis of jury simulation research published in the first 20 years of Law and Human Behavior. The purpose of this part of the paper is twofold: First, to determine the relative frequency with which various research methodologies are being used; and second, to uncover any trends that might be occurring with respect to experimental verisimilitude.

\section{WHO ARE THE JURORS?}

Although college undergraduates are the participants of choice in most human psychological research, empirical findings with undergraduate participants do not always generalize to the population as a whole (Sears, 1986). The issue of the research sample is particularly important in studying jury behavior because of the relative infrequency with which college students serve on actual juries (Bray \& Kerr, 1982) and because of the uses to which some of the findings may ultimately be put (i.e., modifying the court system). There are three approaches to examining the effect of jurors' characteristics on their judgments: correlational studies, done usually within the context of scientific jury selection, that have investigated relationships between various attitudinal and demographic 
variables and jurors' verdicts; experimental studies that have directly compared different samples of mock jurors; and multiexperiment studies that have replicated an empirical result with a sample of a different type from that used to demonstrate the result initially. The findings of each of these approaches are treated in turn.

\section{Scientific Jury Selection}

Hepburn (1980) found that nine demographic variables accounted for only $8 \%$ of the variance in mock jurors' verdicts for a hypothetical murder trial; only two of the variables-age and prior military service-were significantly correlated with participants' verdicts. This relatively weak relationship between demographic factors and mock jurors' judgments reflects the mediating effect of the type of case (Horowitz, 1980). For example, in a rape case, female mock jurors are often more likely than male mock jurors to find a rape defendant guilty (e.g., Ugwuegbu, 1979); when the crime is murder, however, there is no sex difference (Bray \& Noble, 1978).

Studies of actual jurors in trials for a variety of felonies have shown that jurors' sex also interacts with a number of personality measures (Mills \& Bohannon, 1980; Moran \& Comfort, 1982). For example, Mills \& Bohannon (1980) found that socialization scores were positively correlated with guilty verdicts for male jurors, but negatively for female jurors; empathetic male jurors were more likely to acquit, but not empathetic female jurors; and autonomous jurors were more likely to acquit, regardless of sex. With regard to race, two studies of actual criminal trials found a main effect of race, such that Whites were more likely to convict than Blacks (Broeder, 1959; Simon, 1967). Using a simulated rape case, Ugwuegbu (1979) found a more subtle effect of race: White participants judged a Black defendant more culpable than a White defendant, but Black participants displayed the opposite pattern. Similar studies, however, have found an effect of neither sex (Bridgeman \& Marlowe, 1979; Hepburn, 1980) nor race (Hepburn, 1980). Such inconsistent findings led Fulero and Penrod (1990), in a review of the efficacy of scientific jury selection, to conclude that demographic variables were at best only modest predictors of juror verdicts.

\section{Direct Experimental Comparisons}

The research on scientific jury selection has tended not to address the influence of whether jurors are students. As much simulation research employs student mock jurors, this variable is of particular importance to the present discussion of ecological validity (Sears, 1986). A number of experimental studies have compared the verdicts of undergraduate mock jurors to those of a more diverse sample. ${ }^{1}$ The nonstudent samples in these studies

${ }^{1}$ Although the focus of the present article is on the student versus nonstudent comparison, it is worth noting that a few experiments have compared other categories of mock jurors, such as judges and attorneys (e.g., Foley, Adams, \& Goodson, 1996; Simon \& Mahan, 1971). For example, Landsman and Rakos (1994) presented 88 judges and 104 jury pool volunteers the same written summary of a product liability case. The verdicts of the two groups did not differ, and they were affected similarly by exposure to a judicial decision concerning potentially biasing material. 
have been obtained in a variety of ways: from voter registration lists, potential jurors awaiting or having completed jury duty, or a variety of community locales. In all cases, the nonstudent sample is older and more heterogeneous demographically.

Finkel and colleagues have devised an elegant yet simple method for comparing the judgments of students and nonstudents. In several experiments (Finkel \& Duff, 1991; Finkel \& Handel, 1989; Finkel, Hughes, Smith, \& Hurabiell, 1994; Finkel, Hurabiell, \& Hughes, 1993a, b; Finkel, Meister, \& Lightfoot, 1991; Fulero \& Finkel, 1991), student participants were asked to recruit nonstudent participants over the age of 21 years. Both groups of participants completed booklets that described hypothetical trials and asked them to make judgments as though they were real jurors. For example, Finkel \& Handel (1989) compared a sample of undergraduate students $(M$ age $=20$ years, range $=18-36)$ to a nonstudent, adult sample $(M$ age $=45$ years, range $=22-84)$ on their decisions about a number of cases involving the insanity defense. There were no differences in the verdicts reached by the two samples.

This finding is typical of studies that have compared student and nonstudent mock jurors. Table 1 summarizes the results of 26 studies that have addressed the effect of student status on mock jurors' judgments. These studies have presented mock jurors with a range of trial types, including murder - both with (e.g., Fulero \& Finkel, 1991) and without (Elliott \& Robinson, 1991) an insanity defense-armed robbery (e.g., Kramer, Kerr, \& Carroll, 1990), assault (Greene, Wilson, \& Loftus, 1989), and civil cases (e.g., Bornstein \& Rajki, 1994; Casper, Benedict, \& Perry, 1989). They have also included a variety of treatment variables, such as the presence of expert (Cutler, Dexter, \& Penrod, 1989) or hypnotically refreshed testimony (Greene et al., 1989), the definition of insanity (Roberts \& Golding, 1991), the type of pretrial publicity (Kramer et al., 1990), and defendant status (Bray, Struckman-Johnson, Osborne, McFarlane, \& Scott, 1978).

In weighing the generalizability of findings based on undergraduate samples, it is important to ascertain not only whether one group of participants tends to reach harsher or more lenient verdicts; it is also necessary to determine whether sample characteristics interact with other variables of interest (Bray \& Kerr, 1982; Kramer \& Kerr, 1989). For example, in a meta-analysis of the association between authoritarianism and mock jurors' verdicts, Narby, Cutler, and Moran (1993) found that the mock juror sample moderated the relationship. Specifically, authoritarianism was a better predictor of conviction rates among nonstudents than among students (though it was a significant predictor for both samples). Thus, the Results column of Table 1 includes two pieces of information: first, whether there was a main effect of the sample (students vs, nonstudents) on participants' verdicts; and second, whether the sample variable interacted with any treatment variables.

In only 5 of the 26 studies was there a main effect of sample on participants' verdicts. ${ }^{2}$ Simon \& Mahan (1971) found that student-jurors were more likely to find a murder defendant not guilty than were adult prospective jurors; other researchers have found a similar tendency toward greater leniency among students judging both a murder trial that

${ }^{2}$ A fifth study (MacCoun \& Kerr, 1988, Experiment 1) found that although mock juries composed of undergraduates were just as likely to convict as juries composed of community residents - when a final verdict was reached-they were significantly less likely to hang. 
Table 1. Summary of Experiments Directly Comparing Student and Nonstudent Mock Jurors

\begin{tabular}{ll}
\hline \multicolumn{1}{c}{ Study } & \multicolumn{1}{c}{ Samples compared $^{a}$} \\
\hline Berman \& Cutler (1996) & 200 UG vs. $100 \mathrm{CR}$ \\
Bornstein \& Rajki (1994, Exp. 1) & 108 UG vs. $130 \mathrm{CR}$ \\
& \\
$\begin{array}{l}\text { Bray et al. (1978) } \\
\text { Casper et al. (1989) }\end{array}$ & 194 UG vs. $143 \mathrm{CR}$ \\
& 283 UG vs. 253 jurors
\end{tabular}

Crowley et al. (1994)

Cutler et al. (1989)

Cutler et al. (1990)

Elliott \& Robinson (1991, Exp. 3)

Finkel \& Duff (1991, Exp. 1)

Finkel \& Duff (1991, Exp. 2)

Finkel \& Handel (1989)

Finkel et al. (1994, Exp. 2)

Finkel et al. (1993a)

Finkel et al. (1993b)

Finkel et al. (1991)

Fulero \& Finkel (1991)

Greene et al. (1989)

Hosch et al. (1980)

Kramer et al. (1990)

MacCoun \& Kerr (1988, Exp. 1)

Narby \& Cutler (1994, Exp. 2)

Narby \& Cutler (1994, Exp. 3)

Roberts \& Golding (1991)

Schuller \& Hastings (1996)

Simon \& Mahan (1971)

Zickafoose (1997, Exp. 1)
72 UG vs. $72 \mathrm{CR}$

538 UG vs. 96 jurors

321 UG vs. 129 jurors

88 UG vs. $103 \mathrm{CR}$

151 UG vs. $124 \mathrm{CR}$

84 UG vs. $128 \mathrm{CR}$

$124 \mathrm{UG}$ vs. $148 \mathrm{CR}$

87 UG vs. $174 \mathrm{CR}$

$101 \mathrm{UG}$ vs. $69 \mathrm{CR}$

55 UG vs. $72 \mathrm{CR}$

107 UG vs. 162 CR

$201 \mathrm{UG}$ vs. $70 \mathrm{CR}$

108 UG vs. 162 jurors

24 UG vs. 24 CR

174 UG vs. 617 jurors

$168 \mathrm{UG}$ vs. $178 \mathrm{CR}$

62 UG vs. $46 \mathrm{CR}$

30 UG vs. $27 \mathrm{CR}$

145 UG vs. 144 CR

195 UG vs. $202 \mathrm{CR}$

88 UG vs. 69 jurors

82 UG vs. 69 jurors
Results $^{b}$

More NG verdicts by UG; no

interactions

No main effect on verdict; interaction w/race and injury characteristics

No main effect; no interactions

UG awarded more

compensation; no main effect

on punitive damages; no

interactions

No main effect; no interactions

No main effect; no interactions

No main effect on verdict; 2

of 10 interactions significant

No main effect; no interactions

No main effect; no interactions

No main effect; no interactions

No main effect; no interactions

No main effect; no interactions

No main effect; no interactions

No main effect; no interactions

UG less likely to reach verdict of self-defense in 1 of 3 cases; no interactions

No main effect; no interactions

No main effect; no interactions

No main effect; no interactions

No main effect; no interactions

No main effect on verdict,

when reached; UG juries less

likely to hang

No main effect; no interactions

No main effect; no interactions

No main effect; no interactions

More NG verdicts by UG; no

interactions

More NG verdicts by UG; no

interactions

No main effect; no interactions

Note. Unless otherwise noted, results are for effects on mock jurors' verdicts (i.e., guilt or liability). Exp,

Experiment; CR, community residents; UG, undergraduates; NG, not guilty.

${ }^{a}$ Sample sizes refer to the starting number of participants.

${ }^{D}$ The majority of studies reported the results of specific tests for interactions involving sample; in the few cases where such comparisons were not reported, it was assumed that they were not statistically significant.

involved the battered-woman defense (Schuller \& Hastings, 1996) and a robbery trial (Berman \& Cutler, 1996). In the other two studies where differences were found between students and nonstudents, the effect was more ambiguous: Finkel et al. (1991) found that student-jurors were less likely than community-jurors to reach a verdict of self-defense, but in only one of three cases; there was no difference between samples in the other two cases. Using simulated civil cases involving illegal searches, Casper et al. (1989) found 
that student- jurors awarded more in compensation than adults who had been called for jury duty, but they did not award more in punitive damages. Thus, the overwhelming majority of studies that have directly compared different mock juror samples have failed to find consistent differences. When differences have been found, they tend to reflect that studentjurors are a "softer touch," in that they are more likely to find for criminal defendants and award more to civil plaintiffs. This tendency might reflect students' relatively greater idealism, education, and political liberalism (Sears, 1986). In one case, however, studentjurors were harsher, being less receptive to a defense of self-defense (Finkel et al., 1991).

These studies have also tended to find few interactions between the mock juror sample and other variables. In trials where key evidence is offered by an eyewitness, experienced jurors' guilt judgments are influenced more than student-jurors' judgments by whether or not the witness searched through mugshot books and whether or not a weapon was present (Cutler, Penrod, \& Dexter, 1990); however, Cutler et al. also failed to find significant interactions between the participant sample and eight other factors relating to the eyewitness and identification conditions, including the witness's expressed confidence.

Similarly, Bornstein \& Rajki (1994) found that although student-jurors' judgments in a simulated product liability case did not differ from those of a nonstudent, community sample, the sample variable did interact with mock jurors' race and characteristics of the plaintiff's injury. For example, White and minority students' judgments did not differ, but minority nonstudents were more likely to find the defendant liable than White nonstudents. Participants' judgments also varied as a function of certain demographic variables-such as race and socioeconomic status- that tend to be correlated with student versus nonstudent status. However, such interactions are the exception rather than the norm. The remaining 24 studies reported no significant interactions involving the mock juror sample, providing strong evidence that factors at trial affect students and nonstudents in the same way.

\section{Experimental Replications}

A number of studies allow for indirect comparison between students and nonstudents, by performing multiple experiments in which a particular finding is replicated with a different sample. These studies differ from the direct comparisons discussed above in that the mock juror sample is not included as a variable within a single experiment; consequently, there is typically no statistical comparison between samples, allowing only an indirect comparison.

The findings in this category of simulations are consistent with those described above; that is, there are few differences between student and nonstudent samples. For example, Fontaine \& Kiger (1978, Experiment 1) showed student-jurors a videotape of a murder trial in which they varied the defendant's manner of dress and whether he was supervised by an armed guard. Participants judged the defendant's degree of guilt for a more severe charge (i.e., second-degree murder as opposed to manslaughter) as greater when he wore personal dress and was supervised by an armed guard, or wore institutional dress and was unsupervised, compared to the other conditions. In a second experiment, they obtained the same result with an older sample $(M$ age $=45.2$ years $)$ drawn from voter registration lists. 
Other cross-experimental comparisons have shown that student- and community-jurors also respond similarly to age variations in eyewitnesses (Goodman, Golding, Helgeson, Haith, \& Michelli, 1987) and variations in the seriousness of the criminal charge and the severity of the penalty associated with a guilty verdict (Freedman, Krismer, MacDonald, \& Cunningham, 1994). In addition, despite the many respects in which undergraduate students and a communitydrawn sample are likely to differ attitudinally and demographically, measures of individual differences in mock jurors' pretrial bias (e.g., toward the prosecution or the defense) predict verdicts equally well in the two samples (Kassin \& Wrightsman, 1983).

One variable for which uniformity does not appear to be the case is different types of jury instructions. Elwork, Sales, \& Alfini (1977) found that instructions revised to enhance jurors' comprehension had similar effects on mock jurors drawn from both an undergraduate subject pool and the community. However, Halverson, Hallahan, Hart, \& Rosenthal (1997) obtained results that are at odds with those of Elwork et al. In two experiments, Halverson et al. presented mock jurors with an audiotaped DWI trial. In both experiments, they manipulated the type of written jury instructions (standard or revised for better comprehension) and the judge's belief in the defendant's guilt (guilty or not guilty). The judges read the same instructions regardless of their belief, so that only their nonverbal behavior might vary. In Experiment 1, in which 95\% of the mock jurors were students $(M$ age $=19$ years), neither variable exerted an effect on participants' verdicts; nor was there a significant interaction. In Experiment 2, which was virtually identical except for the inclusion of adult mock jurors drawn from the community ( $M$ age $=42$ years), there was again no effect of either variable independently; however, there was a significant interaction, such that the judge's belief (communicated nonverbally) influenced participants' verdicts when the standard instructions were used, but not the revised instructions.

Thus, although the main effect of instructions was the same for both samples (as in Elwork et al., 1977), the instructions' effect did vary across samples when combined with the variable of the judge's belief. There are three reasons not to be overly concerned by this finding: First, the sample size in Halverson et al.'s (1997) second experiment (10-14 per cell) is much smaller than in their first experiment (30 per cell), making the results of the second experiment potentially less stable. Second, nearly half (45\%) of their student sample in Experiment 1 consisted of high school, not college students; thus, it does not clearly shed light on the question of how undergraduates - who are usually over 18 and therefore juryeligible - differ from a community sample. Third, and perhaps most important, it is one of the exceptions among the much larger number of studies which have failed to find differenceseither main effects or interactions - between undergraduate and community samples.

\section{HOW IS THE TRIAL PRESENTED?}

Less research has addressed the variable of the trial medium than characteristics of the mock juror sample. Although a few studies have manipulated the trial medium directly, a greater number have done so indirectly, by replicating a particular finding obtained in one experiment using a different trial medium in a second experiment. 


\section{Direct Experimental Comparisons}

A summary of research that has compared different trial presentation media is displayed in Table 2. These studies have employed a variety of media, ranging from live trials (Hosch, Beck, \& McIntyre, 1980; Miller, 1976; Williams et al., 1975) ${ }^{3}$ to brief written summaries (e.g., Bermant, McGuire, McKinley, \& Salo, 1974; Juhnke, Vought, Pyszczynski, Dane, Losure, \& Wrightsman, 1979). The majority manipulated the medium of the entire trial, in order to test whether trial information as a whole is more persuasive or emotionally arousing depending on the mode of presentation (e.g., Fishfader, Howells, Katz, \& Teresi, 1996). However, several experiments explored different media to assess the effect of specific procedural innovations, such as videotaped (vs. audiotaped or written) testimony (Borgida, 1979) or confessions (Lassiter, Slaw, Briggs, \& Scanlan, 1992). The use of live, as opposed to videotaped, testimony is an especially pertinent, yet controversial, procedural alternative in trials involving child witnesses (Swim, Borgida, \& McCoy, 1993).

As with the variable of participant sample, presentation medium does not have an effect in the majority of cases, exerting a main effect on mock jurors' verdicts in only 3 of 11 studies. Furthermore, the studies where a main effect was found offer conflicting results. Juhnke et al. (1979) found that increased verisimilitude (i.e., going from written summaries or transcripts to audiotape or videotape) produced more guilty verdicts in a simulated trial of a defendant charged with transporting a stolen vehicle across state lines. Bermant et al. (1974), on the other hand, obtained the opposite result; mock jurors exposed to an audiotaped murder trial were less likely to find the defendant guilty than participants who read a less realistic summary or transcript of the trial. It is possible that this inconsistency is due to differences in the type of trial; however, Wilson (1996, Experiment 3) found that mock jurors were more likely to find the defendant in a simulated murder trial guilty when the trial was presented on videotape than when they read a transcript of the trial. Thus, studies that have directly compared presentation media - for either a whole trial or a portion of testimony - fail to offer consistent findings.

These studies explored a number of treatment variables in addition to presentation medium, including the number of eyewitnesses and type of character testimony (Borgida, 1979), the presence or absence of expert testimony (Hosch et al., 1980), and the manner in which evidence damaging to one party was raised (Williams, Bourgeois, \& Croyle, 1993). However, there was only one instance in which the trial medium interacted with one of these other variables. Specifically, Borgida (1979) found that mock jurors in a civil negligence trial who viewed videotaped testimony rendered more pro-plaintiff verdicts when there was only one character witness than when there were relatively many (two or four); however, the

${ }^{3}$ The study by Hosch et al. (1980), which is also included in Table 1, confounded sample with trial medium. Community-jurors made judgments about a live trial, which was subsequently viewed on videotape by a group of student-jurors. Because no single experiment has manipulated sample and trial medium orthogonally, the Hosch et al. study is included in both this and the previous section despite this confound, with the caveat that the null effect found between the two groups could possibly be due to the two variables canceling each other out. 
Table 2. Summary of Experiments Directly Comparing Different Trial Media

\begin{tabular}{|c|c|c|}
\hline Study & Media compared & Results $^{a}$ \\
\hline Bermant et al. (1974) & $\begin{array}{l}\text { Audio w/slides, audio, transcript, } \\
\text { summary }\end{array}$ & $\begin{array}{l}\text { More verdicts of NG for audio } \\
\text { w/slides than summary or } \\
\text { transcript; more verdicts of NG } \\
\text { for audio than summary }\end{array}$ \\
\hline Borgida $(1979)^{b}$ & Video-live, video-read & $\begin{array}{l}\text { No main effect; interaction } \\
\text { w/number of witnesses }\end{array}$ \\
\hline Fishfader et al. (1996) & $\begin{array}{l}\text { Video + reenactment, video, } \\
\text { transcript }\end{array}$ & No main effect; no interactions \\
\hline Hosch et al. (1980) & Live, video & No main effect; no interactions \\
\hline Juhnke et al. (1979) & $\begin{array}{l}\text { B\&W video, audio, transcript, } \\
\text { summary }\end{array}$ & $\begin{array}{l}\text { More verdicts of } G \text { for video } \\
\text { than other media; more verdicts } \\
\text { of } G \text { for audio than summary }\end{array}$ \\
\hline Lassiter et al. (1992) & Video, audio, transcript & No main effect; no interactions \\
\hline Miller (1976, Exp. 1) & Live, video & No main effect \\
\hline Swim et al. $(1993)^{b}$ & Video-live, video-video & No main effect; no interactions \\
\hline Williams et al. (1975) & $\begin{array}{l}\text { Live, color video, B\&W video, } \\
\text { audio, read transcript }\end{array}$ & No main effect \\
\hline Williams et al. (1993, Exp. 1) & Audio, transcript & No main effect; no interactions \\
\hline Wilson (1996, Exp. 1) & Video, transcript & More verdicts of $G$ for video \\
\hline
\end{tabular}

Note. Unless otherwise indicated, results are for effects on mock jurors' verdicts (i.e., guilt or liability). Exp, Experiment; NG, not guilty; G, guilty; B\&W, black-and-white.

${ }^{a}$ The majority of studies reported the results of specific tests for interactions involving sample; in the few cases where such comparisons were not reported, it was assumed that they were not statistically significant.

${ }^{b}$ These studies used a videotaped simulation. For some participants, a key witness's testimony was taped live (video-live); other participants saw the same witness's testimony at trial read by another person (video-read; Borgida, 1979) or given as a videotaped deposition (video-video; Swim et al., 1993). Although Swim et al. found no postdeliberation effects, participants in the video-video condition were more likely to reach a not-guilty predeliberation verdict on one of three charges than participants in the video-live condition.

verdicts of mock jurors who viewed a videotape of someone reading a transcript of the same testimony aloud were unaffected by the number of witnesses. There is some evidence as well that mock jurors' authoritarianism interacts with the trial medium, such that the relationship between authoritarianism and judgments of defendant culpability is stronger for live trials than for less realistic simulations (Narby et al., 1993).

\section{Experimental Replications}

As in the case of the mock juror sample, the majority of indirect comparisons involving trial medium have successfully replicated their major findings despite the change in medium. For example, Ross, Dunning, Toglia, \& Ceci (1990) varied the key witness's age in a 50-min videotaped reenactment of a drug possession trial. Although the witness's age did not affect mock jurors' verdicts, a young adult (21-year-old) witness was perceived as significantly less credible than either an elderly (74-year-old) or a child (8year-old) witness. These findings were replicated in a subsequent experiment in which the identical manipulation was employed, but the same trial was presented as a 15-page written 
transcript. A post hoc comparison of the two experiments showed, furthermore, that trial medium did not affect mock jurors' guilt judgments, nor did it interact with the age of the witness (Ross et al., 1989).

Trial presentation medium has also been found not to alter the effect of a number of other variables. For example, the jury's decision rule has the same effect on mock jurors' verdicts whether the trial is presented in the form of a written summary or staged live (Nemeth, 1977), and whether or not multiple crimes are joined at trial results in the same pattern of verdicts when testimony is offered in either summary or transcript form (Greene \& Loftus, 1985). Trial medium also fails to moderate the effect on mock jurors' verdicts of their attitudes toward the death penalty (Elliott \& Robinson, 1991) or the age of a key eyewitness (Bottoms \& Goodman, 1994; Goodman et al., 1987). Thus, as with research on the juror sample, research on the trial medium tends not to find many differences.

\section{METHODOLOGICAL VARIATIONS IN 20 YEARS OF JURY SIMULATIONS}

In their review of jury simulation research prior to 1979, Bray \& Kerr (1979) found that the most common simulations were those employing student samples and written trial summaries. Given the potentially limited generalizability of such studies, are such "unrealistic" simulations still the norm? Diamond (1997) recently addressed this question, reaching the cautiously optimistic conclusion that current simulations are more realistic than their predecessors. Although Diamond raises and clarifies a number of important issues in jury simulation research — especially with respect to its application to the courts - she does not provide a detailed chronological analysis to support this conclusion. Such an analysis is the purpose of the final section of this paper.

For two reasons, one might expect a trend toward greater verisimilitude over the years: First, because of the persistent concerns about generalizability enunciated above; and second, because technological advancements have increasingly made it easier to incorporate realistic stimuli, such as videotaped trial reenactments, into experimental simulations. In an effort to summarize developments in jury simulation research, the present study chronicles jury simulations published in the first 20 years of Law and Human Behavior (LHB). Although publications in a single journal are obviously not exhaustive, $L H B$ is nonetheless the premier American journal for research on psychology and law. A variety of applied journals (e.g., Applied Cognitive Psychology, Journal of Applied Psychology, Journal of Experimental Psychology: Applied, Journal of Applied Social Psychology), as well as other interdisciplinary journals (e.g., Behavioral Sciences and the Law; Law and Society Review; Psychology, Public Policy, and Law) and law reviews, also publish occasional articles on jury behavior. Because $L H B$ is the primary outlet for this kind of research and is the official journal of the American Psychology-Law Society (Division 41 of the American Psychological Association), it was felt that its contents (especially over a 20-year period) would be sufficiently representative of the field. 
To assess the validity of limiting the chronological analysis to publications in a single journal, I also tabulated all jury simulations published between 1992 and 1996 in the following journals: Behavioral Sciences and the Law (BSL), Journal of Applied Psychology (JAP), Journal of Applied Social Psychology (JASP), and Journal of Personality and Social Psychology (JPSP). During this 5-year period, the number of simulation studies published in these journals was 10 in BSL (6.8\% of all articles), 6 in JAP (1.4\% of all articles), 22 in JASP (3.8\% of all articles), and 2 in JPSP ( $0.2 \%$ of all articles). In comparison, LHB published 44 simulation studies (21.2\% of all articles), more than the other four journals combined. With the exception of the JAP articles, the majority of simulations published in each of these journals employed undergraduate jurors and written trial materials, which was true of LHB as well (see below). Thus, the research methodologies appear not to differ substantially across different publication outlets, making it reasonable to explore trends in LHB as representative of the field as a whole.

\section{Method}

The first 20 years of LHB were reviewed to identify all jury simulation studies. "Jury simulations" were defined as studies in which participants were asked, either explicitly or implicitly, to adopt the role of jurors (Weiten \& Diamond, 1979); that is, they were presented with a trial and asked to make judgments, either individually or after deliberation, that real jurors might make, such as guilt, liability, sentencing, or damages. Thus, studies in which participants read or saw a trial and were asked to report attitudes or make attributions or credibility ratings, but did not in some fashion assess the litigants' guilt, liability, or penalty, were excluded from analysis. Such exclusions were rare; the majority of simulations investigating witness credibility, for instance, also included a guilt measure (e.g., Ross et al., 1990).

Each simulation was classified in terms of the mock juror sample (undergraduates, community adults, or real jurors awaiting or having completed jury duty) and the medium in which the trial was presented (written summary, transcript, audiotape, videotape, or live). In the event that a study included more than one sample type or different mediaeither within a single experiment or across experiments-it was counted as one-half for each category (no study included more than two sample populations or media). ${ }^{4}$

\section{Results}

\section{Summary of the Data}

In the first 20 years of LHB (1977-1996), there were 113 jury simulation studies. ${ }^{5}$ Thirty-two of these studies $(28.3 \%)$ were multiple-experiment papers. Jury simulations

${ }^{4}$ Eighteen studies permitted a comparison of different participant samples (14 within a single experiment and 4 across experiments), while 8 studies ( 4 within a single experiment, 4 across experiments) permitted a comparison of different media. All of these studies are summarized in the preceding sections and accompanying tables.

${ }^{5} \mathrm{~A}$ complete list of the simulations is available from the author. 
comprised $19.4 \%$ of the total number of research articles during the period. ${ }^{6}$ The distribution of studies across these samples and media is shown in Table 3. As the table indicates, the majority of simulations are as unrealistic as they were when the field was reviewed 20 years ago (Bray \& Kerr, 1979; Davis et al., 1977). Nearly two-thirds of the studies $(65 \%)$ had students play the role of jurors, and over half $(55 \%)$ presented the trial in written form (summary or transcript). Only two studies had participants observe and make judgments about a case that involved live actors (Borgida, DeBono, \& Buckman, 1990; Hosch et al., 1980).

\section{Chronological Trends}

Because there were very few simulations published in some years (no studies in 1982, and one each in 1977, 1981, 1986, and 1992), the 20 years were divided into ten 2-year intervals to provide greater stability for exploring trends. The bottom line in Fig. 1 shows the percentage of total articles that were jury simulations. This percentage ranges from a low of $2 \%$ in 1981-1982 to a high of $35.6 \%$ in 1989-1990. There has been a slight trend over time toward the inclusion of a greater proportion of articles on jury behavior, as indicated by the positive slope of the regression line that best fits these data points (slope $=1.86 ; R^{2}$ $=.31$ ). Although the number of jury simulations published in a single journal is but one indication of the amount of research being conducted in the field, it nonetheless suggests that jury simulation research is alive and well (Diamond, 1997; Thompson, 1993).

Table 3. Cumulative Frequency of Mock Juror Samples and Trial Media in Law and Human Behavior Jury Simulations (1977-1996)

\begin{tabular}{|c|c|c|c|c|c|c|}
\hline & \multicolumn{4}{|c|}{ Mock juror sample } & & \\
\hline & Students & Community & Jurors & Total & & \\
\hline \multirow{4}{*}{$\begin{array}{l}N \\
\%\end{array}$} & 73 & 23.5 & 15.5 & 112 & & \\
\hline & 65.2 & 21.0 & 13.8 & 100 & & \\
\hline & \multicolumn{6}{|c|}{ Trial presentation medium } \\
\hline & Summary & Transcript & Audiotape & Videotape & Live & Total \\
\hline$N$ & 51 & 11.5 & 11.5 & 37.5 & 1.5 & 113 \\
\hline$\%$ & 45.1 & 10.2 & 10.2 & 33.2 & 1.3 & 100 \\
\hline
\end{tabular}

Note. Half points were awarded for studies that employed two different sample types or media. Total Ns differ because one study failed to specify who the mock jurors were.

${ }^{\circ}$ Percentages were used as the dependent measure, rather than frequencies, because of the increase from four to six issues that took place in 1990 (Volume 14). To compute this percentage, it was necessary to determine (for the denominator) what constituted a "research article." A fairly liberal definition was employed, such that the only items excluded from the count were editorials, bibliographic searches (a short-lived feature of the journal in 1983), self-standing appendices, book reviews, obituaries, and adversary forums. This classification scheme is admittedly arbitrary, but it includes all articles reporting original, substantive research (theoretical or empirical) without being overly conservative. 


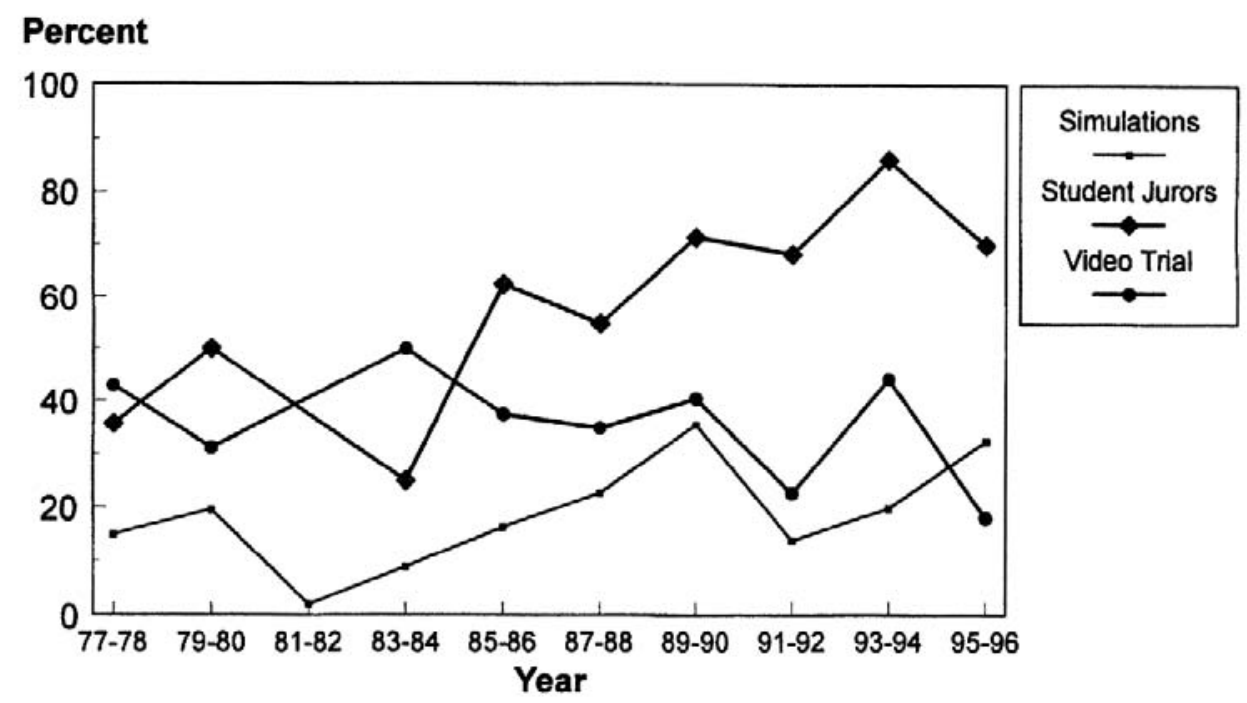

Fig. 1. Percentage of jury simulations (of total articles), percentage of simulations using student-jurors, and percentage of simulations using videotape trials, by 2 -year intervals.

Figure 1 also shows, as a function of time, the percentage of simulations that employed student-jurors and that presented videotape trials (there are no data points for 1981-1982 because there was only one simulation in these two years combined). As indicated in the figure, videotape simulations are not becoming more common, despite the lowered cost and increased availability of video equipment compared to 20 years ago. In fact, a regression equation indicates that videotape trials are actually becoming somewhat less common over time (slope $=-1.5, R^{2}=.20$ ). In addition, the percentage of simulations with students as mock jurors is clearly increasing. A regression line fitting the data for the percentage of simulations using student jurors has a strongly positive slope of $4.9\left(R^{2=} .63\right)$. Thus, jury simulations in Law and Human Behavior are, if anything, becoming less realistic over time. The "state of the science" may indeed be one of increasing sophistication in some respects (Diamond, 1997; Thompson, 1993), but this sophistication has not been accompanied by increasing verisimilitude in terms of who the mock jurors are and how the simulated trial is presented to them.

\section{SUMMARY AND CONCLUSIONS}

Despite the prevalence of simulations in studying jury behavior, some research has been conducted on real jurors as well. Broadly speaking, there have been two approaches to studying real jurors. In one approach, jurors are questioned about the trial in which they were involved after completing jury duty (e.g., Moran \& Comfort, 1982; Reifman, Gusick, \& Ellsworth, 1992; Sandys \& Dillehay, 1995). Al-though this method has the drawback of potential memory bias in jurors' retrospective reports, it tends to support the findings of simulation studies. For example, Reifman et al. (1992) found that, as with mock jurors, real jurors' comprehension of the instructions that they receive at trial is not very good. 
The second approach, which is rarer, is to manipulate variables of interest within actual trials. Heuer \& Penrod (1988, 1994a, b) are the leading practitioners of this method, having investigated the effects of procedural variations such as whether jurors in actual cases are allowed to take notes or ask questions during trial. Such efforts are to be commended and encouraged; however, because of the enormous logistical problems inherent in such research, simulation studies are likely to continue as the norm. Simulations are also popular because of the better opportunities they afford for preserving experimental control, testing specific psychological theories or procedural innovations that could not be practically implemented in a real courtroom, and so forth (Bray \& Kerr, 1979; Diamond, 1997; Weiten \& Diamond, 1979).

The propriety of conducting simulation research in an attempt to generalize to the behavior of real jurors is a serious issue, and one that raises a number of important questions. As noted by Diamond (1997), more research on methodological variations is needed, as well as a better theoretical basis for predicting when and why different methodologies will affect mock jurors' decisions. It is striking that only 26 and 11 published studies could be found comparing, respectively, different participant samples and trial presentation media, in a field containing several hundred studies at least (113 in the first 20 years of Law and Human Behavior alone). Nonetheless, despite the variety of approaches to conducting jury simulation research, few differences have been found as a function of either who the mock jurors are or how the mock trial is presented. Thus, although simulations have not become more realistic over time, it may not matter much. Two decades of additional research support Bray \& Kerr's (1979, p. 117) conclusion, regarding the ecological validity of jury simulations, that "the pattern of results does not warrant the negative reactions of some evaluators." These findings bode well for the feasibility of generalizing from simulation studies to the behavior of real jurors.

Although these findings should be reassuring to researchers conducting simulation studies, a note of caution is warranted as well, for two reasons. First, the courts have not welcomed psycholegal research findings with open arms, especially when they derive from methods that are neither very realistic nor representative of actual legal processes (Diamond, 1997; Ellsworth, 1988). Thus, researchers interested in the practical applications of their results would be well advised to adhere to Diamond's (1997) recommendation to conduct "Stage One" research with relatively "easy" methods (e.g., students, brief written trials), to be replicated in "Stage Two" research with harder, more representative methods (e.g., real jurors or community adults, videotaped trials).

Second, with regard to the issues reviewed in the present paper, no research has manipulated the mock juror sample and trial medium in the same experiment, in order to investigate possible interactions between these variables. In addition, the present review addressed only two aspects of simulation research. The potential impact of other factors, such as variations in whether or not the mock jurors deliberate and the consequentiality of the task, requires further investigation (see Diamond, 1997, for a review). On the whole, relatively little research on jury decision making has directly addressed issues of validity; of that which has, while the majority has tended to find few differences as a function of verisimilitude, such null findings are not universal. Questions of ecological validity are 
ultimately empirical in nature (Kramer \& Kerr, 1989). While the present review suggests that a jury deliberating on the ecological validity of jury simulation research would lean toward a finding in favor of the null hypothesis, the courts are demanding more data and applying a near-unanimous decision rule (Diamond, 1997).

\section{ACKNOWLEDGMENTS}

A portion of this paper was presented at the 1998 meeting of the American PsychologyLaw Society. I am grateful to Kerri Dunn for her assistance in locating relevant articles and to Edie Greene and Neal Feigenson for helpful comments on an earlier version of the manuscript.

\section{REFERENCES}

Berman, G. L., \& Cutler, B. L. (1996). Effects of inconsistencies in eyewitness testimony on mock-juror decision making. Journal of Applied Psychology, 81, 170-177.

Bermant, G., McGuire, M., McKinley, W., \& Salo, C. (1974). The logic of simulation in jury research. Criminal Justice and Behavior, 1, 224-233.

Borgida, E. (1979). Character proof and the fireside induction. Law and Human Behavior, 3, 189-202.

Borgida, E., DeBono, K. G., \& Buckman, L. A. (1990). Cameras in the courtroom: The effects of media coverage on witness testimony and juror perceptions. Law and Human Behavior, 14, 489-509.

Bornstein, B. H., \& Rajki, M. (1994). Extra-legal factors and product liability: The influence of mock jurors' demographic characteristics and intuitions about the cause of an injury. Behavioral Sciences and the Law, $12,127-147$.

Bottoms, B. L., \& Goodman, G. S. (1994). Perceptions of children's credibility in sexual assault cases. Journal of Applied Social Psychology, 24, 702-732.

Bray, R. M., \& Kerr, N. L. (1979). Use of the simulation method in the study of jury behavior: Some methodological considerations. Law and Human Behavior, 3, 107-119.

Bray, R. M., \& Kerr, N. L. (1982). Methodological considerations in the study of the psychology of the courtroom. In N. L. Kerr \& R. M. Bray (Eds.), The psychology of the courtroom (pp. 287-323). New York: Academic Press.

Bray, R. M., \& Noble, A. M. (1978). Authoritarianism and decisions of mock juries: Evidence of jury bias and group polarization. Journal of Personality and Social Psychology, 36, 1424-1430.

Bray, R. M., Struckman-Johnson, C., Osborne, M. D., McFarlane, J. B., \& Scott, J. (1978). The effects of defendant status on the decisions of student and community juries. Social Psychology, 41, 256-260.

Bridgeman, D. L., \& Marlowe, D. (1979). Jury decision making: An empirical study based on actual felony trials. Journal of Applied Psychology, 64, 91-98.

Broeder, D. W. (1959). The University of Chicago Jury Project. Nebraska Law Review, 88, 744-760.

Carroll, J. S., Kerr, N. L., Alfini, J. J., Weaver, E M., MacCoun, R. J., \& Feldman, V. (1986). Free press and fair trial: The role of behavioral research. Law and Human Behavior, 10, 187-201.

Casper, J. D., Benedict, K., \& Perry, J. L. (1989). Juror decision making, attitudes, and the hindsight bias. Law and Human Behavior; 13, 291-310.

Crowley, M. J., O'Callaghan, M. G., \& Ball, P. J. (1994). The juridical impact of psychological expert testimony in a simulated child sexual abuse trial. Law and Human Behavior, 18, 89-105.

Cutler, B. L., Dexter, H. R., \& Penrod, S. D. (1989). Expert testimony and jury decision making: An empirical analysis. Behavioral Sciences and the Law, 7, 215-225.

Cutler, B. L., Penrod, S. D., \& Dexter, H. R. (1990). Juror sensitivity to eyewitness identification evidence. Law and Human Behavior, 14, 185-191.

Davis, J. H., Bray, R. M., \& Holt, R. W (1977). The empirical study of decision processes in juries: A critical review. In J. L. Tapp \& E J. Levine (Eds.), Law, justice, and the individual in society: Psychological and legal issues (pp. 326-361). New York: Holt, Rinehart \& Winston.

Diamond, S. S. (Ed.) (1979). Simulation research and the law [Special issue]. Law and Human Behavior, 3(1/2).

Diamond, S. S. (1997). Illuminations and shadows from jury simulations. Law and Human Behavior, 21, 561571.

Elliott, R., \& Robinson, R. J. (1991). Death penalty attitudes and the tendency to convict or acquit: Some data. Law and Human Behavior, 15, 389-404.

Ellsworth, E C. (1988). Unpleasant facts: The Supreme Court's response to empirical research on capital 
punishment. In K. C. Haas and J. A. Inciardi (Eds.), Challenging capital punishment: Legal and social science approaches. Newbury Park, CA: Sage.

Elwork, A., Sales, B. D., \& Alfini, J. J. (1977). Juridic decisions: In ignorance of the law or in light of it? Law and Human Behavior, 1, 163-189.

Finkel, N. J., \& Duff, K. B. (1991). Felony-murder and community sentiment: Testing the Supreme Court's assertions. Law and Human Behavior, 15, 405-429.

Finkel, N. J., \& Handel, S. E (1989). How jurors construe "insanity." Law and Human Behavior, 13, 41-59.

Finkel, N. J., Hughes, K. C., Smith, S. E, \& Hurabiell, M. L. (1994). Killing kids: The juvenile death penalty and community sentiment. Behavioral Sciences and the Law, 12, 5-20.

Finkel, N. J., Hurabiell, M. L., \& Hughes, K. C. (1993a). Right to die, euthanasia, and community sentiment: Crossing the public/private boundary. Law and Human Behavior, 17, 487-506.

Finkel, N. J., Hurabiell, M. L., \& Hughes, K. C. (1993b). Competency, and other constructs, in right to die cases. Behavioral Sciences and the Law, 11, 135-150.

Finkel, N. J., Meister, K. H., \& Lightfoot, D. M. (1991). The self-defense defense and community sentiment. Law and Human Behavior, 15, 585-602.

Fishfader, V L., Howells, G. N., Katz, R. C., \& Teresi, E S. (1996). Evidential and extralegal factors in juror decision: Presentation mode, retention, and level of emotionality. Law and Human Behavior, 19, 565-572.

Foley, L. A, Adams, A. M., \& Goodson, J. L. (1996). The effect of race on decisions by judges and other officers of the court. Journal of Applied Social Psychology, 26, 1190-1212.

Fontaine, G., \& Kiger, R. (1978). The effects of defendant dress and supervision on judgments of simulated jurors: An exploratory study. Law and Human Behavior, 2, 63-71.

Freedman, J. L., Krismer, K., MacDonald, J. E., \& Cunningham, J. A. (1994). Severity of penalty, seriousness of the charge, and mock jurors' verdicts. Law and Human Behavior, 18, 189-202.

Fulero, S. M., \& Finkel, N. J. (1991). Barring ultimate issue testimony. Law and Human Behavior, 15, $495-507$.

Fulero, S. M., \& Penrod, S. D. (1990). Attorney jury selection folklore: What do they think and how can psychologists help? Forensic Reports, 3, 233-259.

Gerbasi, K. C., Zuckerman, M., \& Reis, H. T (1977). Justice needs a new blindfold: A review of mock jury research. Psychological Bulletin, 84, 323-345.

Goodman, G. S., Golding, J. M., Helgeson, V. S., Haith, M. M., \& Michelli, J. (1987). When a child takes the stand: Jurors' perceptions of children's eyewitness testimony. Law and Human Behavior, 9, 193-207.

Greene, E., \& Loftus, E. F. (1985). When crimes are joined at trial. Law and Human Behavior, 11, $27-40$.

Greene, E., Wilson, L., \& Loftus, E. F. (1989). Impact of hypnotic testimony on the jury. Law and Human Behavior, 13, 61-78.

Halverson, A. M., Hallahan, M., Hart, A. J., \& Rosenthal, R. (1997). Reducing the biasing effects of judges' nonverbal behavior with simplified jury instruction. Journal of Applied Psychology, 82, 590-598.

Hepburn, J. R. (1980). The objective reality of evidence and the utility of systematic jury selection. Law and Human Behavior, 4, 89-101.

Heuer, L., \& Penrod, S. (1988). Increasing jurors' participation in trials: A field experiment with juror notetaking and question asking. Law and Human Behavior, 12, 231-261.

Heuer, L., \& Penrod, S. (1994a). Trial complexity: A field investigation of its meaning and its effects. Law and Human Behavior, 18, 29-51.

Heuer, L., \& Penrod, S. (1994b). Juror notetaking and question asking during trials: A national field experiment. Law and Human Behavior, 18, 121-150.

Horowitz, I. A. (1980). Juror selection: A comparison of two methods in several criminal cases. Journal of Applied Social Psychology, 10, 86-99.

Hosch, H. M., Beck, E. L., \& McIntyre, E (1980). Influence of expert testimony regarding eyewitness accuracy on jury decisions. Law and Human Behavior, 4, 287-296.

Juhnke, R., Vought, C., Pyszczynski, T. A., Dane, F. C., Losure, B. D., \& Wrightsman, L. S. (1979). Effects of presentation mode upon mock jurors' reactions to a trial. Personality and Social Psychology Bulletin, 5, 36-39.

Kalven, H., \& Zeisel, H. (1966). The American jury. Boston: Little, Brown.

Kassin, S. M., \& Wrightsman, L. S. (1983). The construction and validation of a juror bias scale. Journal of Research in Personality, 17, 423-442.

Ken, N. J., Nerenz, D. R., \& Herrick, D. (1979). Role playing and the study of jury behavior. Sociological Methods and Research, 7, 337-355.

Konecni, V. J., \& Ebbesen, E. B. (1979). External validity of research in legal psychology. Law and Human Behavior, 3, 39-70.

Kramer, G. E, \& Kerr, N. L. (1989). Laboratory simulation and bias in the study of juror behavior: A methodological note. Law and Human Behavior, 13, 89-99. 
Kramer, G. E, Kerr, N. L., \& Carroll, J. S. (1990). Pretrial publicity, judicial remedies, and jury bias. Law and Human Behavior, 14, 409-438.

Landsman, S., \& Rakos, R. (1994). A preliminary inquiry into the effect of potentially biasing information on judges and jurors in civil litigation. Behavioral Sciences and the Law, 12, 113-126.

Lassiter, G. D., Slaw, R. D., Briggs, M. A., \& Scanlan, C. R. (1992). The potential for bias in videotaped confessions. Journal of Applied Social Psychology, 22, 1838-1851.

MacCoun, R. J., \& Kerr, N. L. (1988). Asymmetric influence in mock jury deliberation: Jurors' bias for leniency. Journal of Personality and Social Psychology, 54, 21-33.

Miller, G. R. (1976). The effects of videotaped trial materials on juror response. In G. Bermant, C. Nemeth, \& N. Vidmar (Eds.), Psychology and the law (pp. 185-208). Lexington, MA: Heath.

Mills, C. J., \& Bohannon, W. E. (1980). Character structure and jury behavior: Conceptual and applied implications. Journal of Personality and Social Psychology, 38, 662-667.

Moran, G., \& Comfort, J. C. (1982). Scientific juror selection: Sex as a moderator of demographic and personality predictors of impaneled felony juror behavior. Journal of Personality and Social Psychology, 43, 10521063.

Narby, D. J., \& Cutler, B. L. (1994). Effectiveness of voir dire as a safeguard in eyewitness cases. Journal of Applied Psychology, 79, 724-729.

Narby, D. J., Cutler, B. L., \& Moran, G. (1993). A meta-analysis of the association between authoritarianism and jurors' perceptions of defendant culpability. Journal of Applied Psychology, 78, 34-42.

Nemeth, C. (1977). Interactions between jurors as a function of majority vs. unanimity decision rules. Journal of Applied Social Psychology, 7, 38-56.

Reifman, A., Gusick, S. M., \& Ellsworth, P. C. (1992). Real jurors' understanding of the law in real cases. Law and Human Behavior, 16, 539-554.

Roberts, C. E, \& Golding, S. L. (1991). The social construction of criminal responsibility and insanity. Law and Human Behavior, 15, 349-376.

Ross, D. E, Dunning, D., Toglia, M. P., \& Ceci, S. J. (1989). Age stereotypes, communication modality, and mock jurors' perceptions of the child witness. In S. J. Ceci, D. F. Ross, \& M. P. Toglia (Eds.), Perspectives on children's testimony (pp. 37-56). New York: Springer-Verlag.

Ross, D. E, Dunning, D., Toglia, M. P., \& Ceci, S. J. (1990). The child in the eyes of the jury: Assessing mock jurors' perceptions of the child witness. Law and Human Behavior, 14, 5-23.

Sandys, M., \& Dillehay, R. C. (1995). First-ballot votes, predeliberation dispositions, and final verdicts in jury trials. Law and Human Behavior, 19, 175-195.

Schuller, R. A, \& Hastings, P A. (1996). Trials of battered women who kill: The impact of alternative forms of expert evidence. Law and Human Behavior, 20, 167-187.

Sears, D. O. (1986). College sophomores in the laboratory: Influences of a narrow data base on social psychology's view of human nature. Journal of Personality and Social Psychology, 51, 515-530.

Simon, R. J. (1967). The jury and the defense of insanity. Boston: Little, Brown.

Simon, R. J., \& Mahan, L. (1971). Quantifying burdens of proof: A view from the bench, the jury, and the classroom. Law and Society Review, 5, 319-330.

Swim, J. K., Borgida, E., \& McCoy, K. (1993). Videotaped versus in-court witness testimony: Does protecting the child witness jeopardize due process? Journal of Applied Social Psychology, 23, 603-631.

Thompson, W. C. (1989). Death qualification after Wainwright v. Wilt and Lockhart v. McCree. Law and Human Behavior, 13, 185-215.

Thompson, W. C. (1993). Research on jury decision making: The state of the science. In N. J. Castellan (Ed.), Individual and group decision making: Current issues (pp. 203-218). Hillsdale, NJ: Erlbaum.

Ugwuegbu, D. C. E. (1979). Racial and evidential factors in juror attribution of legal responsibility. Journal of Experimental Social Psychology, 15, 133-146.

Weiten, W., \& Diamond, S. S. (1979). A critical review of the jury simulation paradigm: The case of defendant characteristics. Law and Human Behavior, 3, 71-93.

Williams, G. R., Farmer, L. C., Lee, R. E., Cundick, B. P., Howell, R. J., \& Rooker, C. K. (1975). Juror perceptions of trial testimony as a function of the method of presentation. Brigham Young University Law Review, 2, 375-421.

Williams, K. D., Bourgeois, M. J., \& Croyle, R. T. (1993). The effects of stealing thunder in criminal and civil trials. Law and Human Behavior, 17, 597-609.

Wilson, J. R. (1996). Putting the trial back into pretrial publicity: The medium is the message. Unpublished master's thesis, Louisiana State University, Baton Rouge.

Zickafoose, D. J. (1997). Double discounting: The effects of comparative negligence. Unpublished master's thesis, Louisiana State University, Baton Rouge. 